\title{
Application of IR technique and FEM for estimation of stress components at the stress concentrator in the metals
}

\author{
by A. Terekhina*, A. Kostina* and O. Plekhov*
}

* Institute of Continuous Media Mechanics of Ural branch of Russian Academy of Sciences, 1.Ac. Korolev st., 614013 Perm, Russia, tai_mm_90@mail.ru

\section{Abstract}

This work is devoted to development of an experimental-numerical hybrid methodology for the determination of all stress components from the first stress invariant based on the infrared thermography data. The methodology is based on a combination of thermoelastic stress analysis and numeric simulation of stress-strain state (FEM). The technique is illustrated by calculation of stress distribution near concentrators of different geometry.

\section{Introduction}

In recent decades, many authors have been actively investigated the process of heat dissipation due to the material structure evolution under cyclic and quasistatic loading. The technique of infrared scanning can be regarded as the universal method which can be actively apply during mechanical testing of the materials for obtain the detail information about the process of material structure evolution, damage accumulation and damage-fracture transition in solids. This method also has the advantage that it is a non-contact method and it is not require lengthy and complex surface preparation, this method become especially significant in diagnosing objects with impossible or limited direct access [2].

The use of technique infrared scanning for the experimental analysis of thermoelastic stresses is useful and valuable technique because it provides field information on a specimen surface or the area of interest. Since in the case of thermoelastic stress analysis with IR-technique we can determine only the sum of principal stresses, and thus the stress components themselves cannot be obtained directly. It is interesting to investigate the possibilities of development of a numerical-experimental method for the calculating the other stress components.

The present work is devoted to the determination of all stress components by using thermoelastic stress analysis and finite elements method. The methodology was based on the experimental measurement of the first stress invariant of stress tensor and determining all components of the stress based on the solution of corresponding boundary problem. Attempt to represent stress fields on the whole studied area lead to the necessity to solve mathematical physics problems with boundary conditions stated on the part of area, in which the given problem is considered. For the first time the solution of the problem using the first invariant of stress described Murakami, and Y. Yoshimura, M. in 1997 [3]. Development of this method is the usefulness and applicability of the thermoelastic stress analyzer will be remarkably extended and make method is applicable to most practically important problems.

\section{Material and experimental conditions}

The material under investigation is $08 \times 18 \mathrm{H} 10$ steel. The chemical composition is presented in table 1 . For quasi-static tensile were used the specimen with an edge notch (figure 1). The specimens were manufactured from the sheets $3 \mathrm{~mm}$ thick. The working part of the specimen was $55 \times 200 \mathrm{~mm}$. The geometry of specimen and peculiarities of experimental condition are described in [1].

Table 1. The chemical composition of $08 \times 18 \mathrm{H} 10$ steel (\%).

\begin{tabular}{|c|c|c|c|c|c|c|c|c|}
\hline $\mathrm{C}$ & $\mathrm{Si}$ & $\mathrm{Mn}$ & $\mathrm{Ni}$ & $\mathrm{S}$ & $\mathrm{P}$ & $\mathrm{Cr}$ & $\mathrm{Ti}$ & $\mathrm{Cu}$ \\
\hline 0.08 & 0.8 & 2 & $9-11$ & 0.02 & 0.035 & $17-19$ & 0.5 & 0.3 \\
\hline
\end{tabular}

The tensile tests were carried out using a Bi-00-100 servohydraulic testing machine $(100 \mathrm{kN})$. The temperature evolution was recorded by infrared camera Flir SC5000. Table 2 shows the main specifications of infrared camera Flir SC5000. The calibration of the camera was made, based on the standard calibration table.

The experimental setup is shown in figure 2.

Table 2. Mainspecifications of Flir SC5000

\begin{tabular}{|l|l|}
\hline Waveband & $2.5-5 \mu \mathrm{m}$ \\
\hline Pixel resolution & $320 \times 256$ \\
\hline Pitch & $30 \mu \mathrm{m} / 15 \mu \mathrm{m}$ \\
\hline NETD & $<20 \mathrm{mK}$ \\
\hline Max Full Frame rate & upto $380 \mathrm{~Hz}$ \\
\hline Temperature calibration range & available from $-20{ }^{\circ} \mathrm{C}$ to up to $3000{ }^{\circ} \mathrm{C}$ \\
\hline Temperature measurement accuracy & $\pm 1{ }^{\circ} \mathrm{C}$ or $\pm 1 \%$ \\
\hline
\end{tabular}


http://dx.doi.org/10.21611/qirt.2014.176

\begin{tabular}{|l|l|}
\hline Extended dynamic range & MultilT ${ }^{\text {TM}} /$ TemperatureRangeExtension (TRE) \\
\hline Filter wheel & wheel 4 slotsmotorizedremovable \\
\hline Field of view & $\begin{array}{l}\text { From } 42^{\circ} \times 34^{\circ}(12 \mathrm{~mm}) \text { to } 10^{\circ} \times 8^{\circ}(54 \mathrm{~mm}) \text { up to } \times 5 \\
\text { microscope lens }\end{array}$ \\
\hline Integration time & $1 \mu$ s to $20 \mathrm{~ms}$ variable by $1 \mu \mathrm{ss}$ step \\
\hline Spectral range & $3-5 \mu \mathrm{m}$ \\
\hline
\end{tabular}

The surface of the specimens was polished in several stages by the abrasive paper (at the final stage of polishing the grit size does not exceed $3 \mu \mathrm{m}$ ). Before starting the experiment, the polished surface was covered by a thin layer of amorphous carbon.

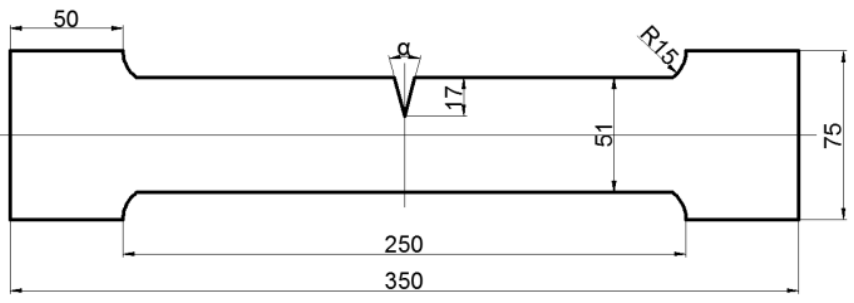

Fig.1. Geometry of specimens used for tensile tests $\left(\alpha=30^{\circ}, 60^{\circ}, 90^{\circ}\right)$.

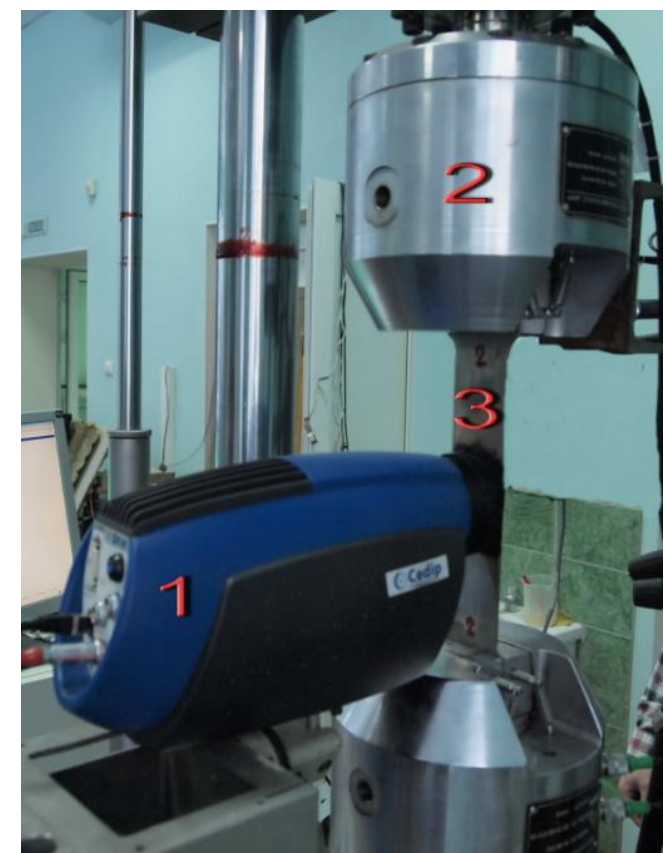

Fig. 2. Experimental setup (1 - infrared camera Flir SC5000, 2 - servohydraulic testing machine Bi-00-100, 3 specimen).

\section{The resolution of all stress components}

The heat generation in the elastic range of deformation of an elastic body under adiabatic loading can be proportionally correlated with sum of the principal stresses which is the first invariant of stress tensor is expressed as (1):

$$
\mathrm{J}_{1}=\sigma_{1}+\sigma_{2}+\sigma_{3} \text {. }
$$
equation:

The temperature data obtained by the infrared camera are related to the first stress invariant by the following

$$
\Delta \mathrm{T}=-\frac{\alpha \cdot \mathrm{V}_{0}}{\mathrm{C}_{\mathrm{v}}} \cdot \mathrm{T} \cdot \mathrm{J}_{1},
$$

Where $\Delta \mathrm{T}$ - temperature change, $\alpha$ - coefficient of thermal expansion, $\mathrm{V}_{0}$ - molar volume, $\mathrm{C}_{\mathrm{v}}$ - molar heat at constant volume, $\mathrm{T}$ - absolute temperature, $\mathrm{J}_{1}$ - the first stress invariant.

Temperature distribution and distribution of the first invariant of the stress for a sample with a notch shown 
inFig. 3.
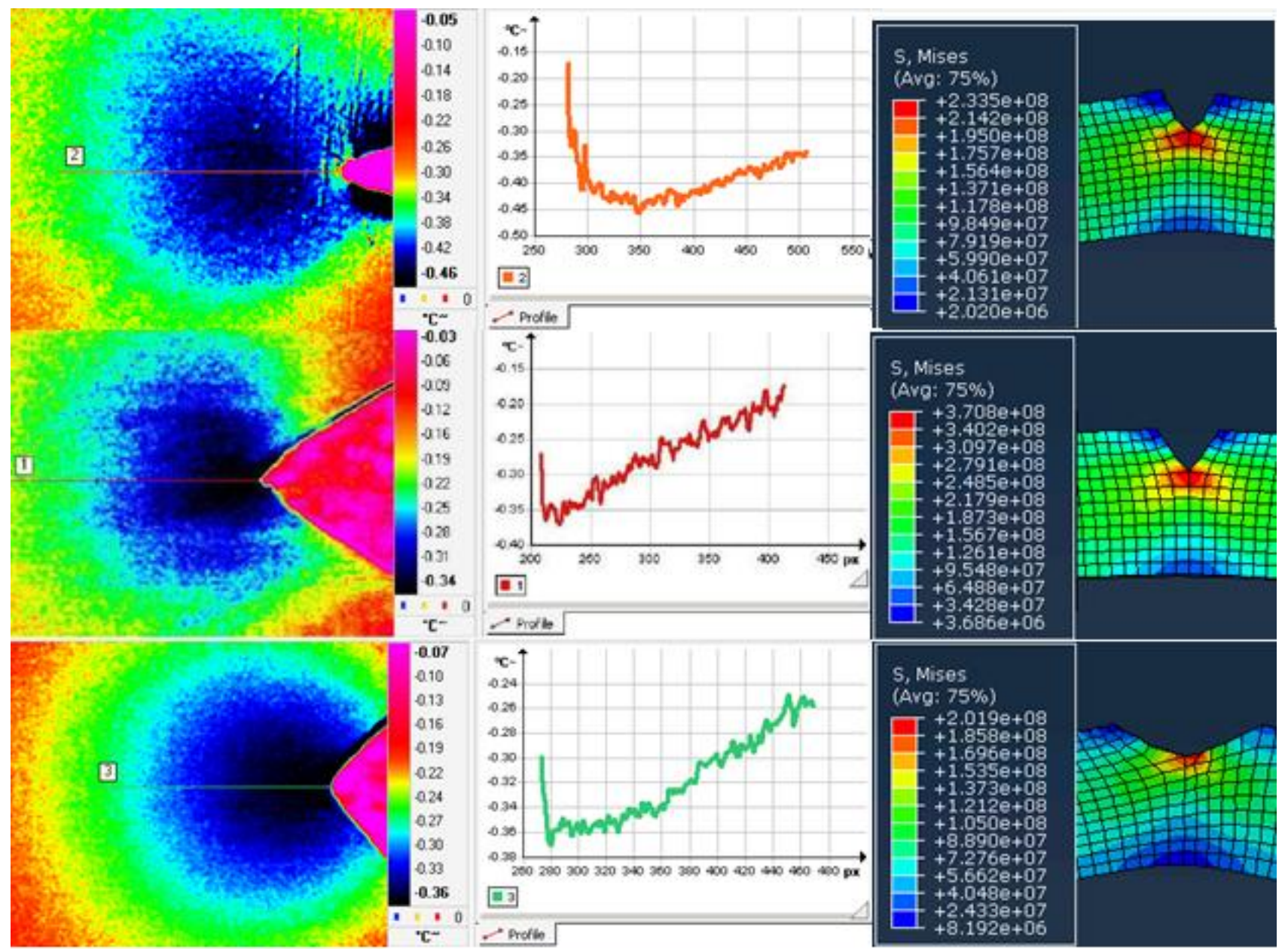

Fig. 3. Temperature distribution and distribution of the first invariant of the stress for different notch radius. Experimental results (a), numerical simulation (b).

The experimentally measured (calculated) the first stress invariant (J1) at M points on the surface specimen gives us a possibility to determine the load boundary condition from the measured values of $\mathrm{J} 1$ [3]. Then, based on the results of numerical solution of corresponding boundary problem we can determine all stress components at any point inside of the investigated area.

The methodology for determine the load boundary:

1) As shown in Fig. 4, choose sufficient points along the boundary. A unit normal force and then a unit tangential force is applied to each point in turn (from $j=1$ to $j=N$ ).

2) To calculate the value of stress invariant $j_{1 \mathrm{ij}}^{*}$ at point i produced by the unit force at point $\mathrm{j}$.

3) The true boundary condition $P_{j}$ along the boundary should make the following difference zero.

$$
\mathrm{e}_{\mathrm{i}}=\mathrm{j}_{1 \mathrm{i}}-\sum_{\mathrm{j}=1}^{\mathrm{N}} \mathrm{j}_{1 \mathrm{ij}}^{*} \mathrm{P}_{\mathrm{j}}, \mathrm{i}=\overline{1, \mathrm{M}}, \mathrm{j}=\overline{1, \mathrm{~N}}
$$

4) To find the optimum values of $P_{j}$ in a rational way, we apply the least square method to $e_{i}$. We define $S$ as the sum of $\mathrm{e}_{\mathrm{i}}^{2}$ by

$$
\mathrm{S}=\sum_{\mathrm{i}=1}^{\mathrm{M}}\left(\mathrm{e}_{\mathrm{i}}^{2}\right)
$$

Thus, the optimum values of $\mathrm{P}_{\mathrm{j}}$ must satisfy:

$$
\frac{\partial \mathrm{S}}{\partial \mathrm{P}_{\mathrm{j}}}=0
$$


Equation (5) is a set of $\mathrm{N}$ linear simultaneous equations. Solving it, we can determine $\mathrm{P}_{j}$. Once the values $\mathrm{P}_{j}$ are determined we can calculate the stress components at any point on the plate by superimposing the stress components induced by $\mathrm{P}_{\mathrm{j}}$ along the boundary. For the calculation of $\mathrm{j}_{1 \mathrm{ij}}^{*}$ FEM may be used.

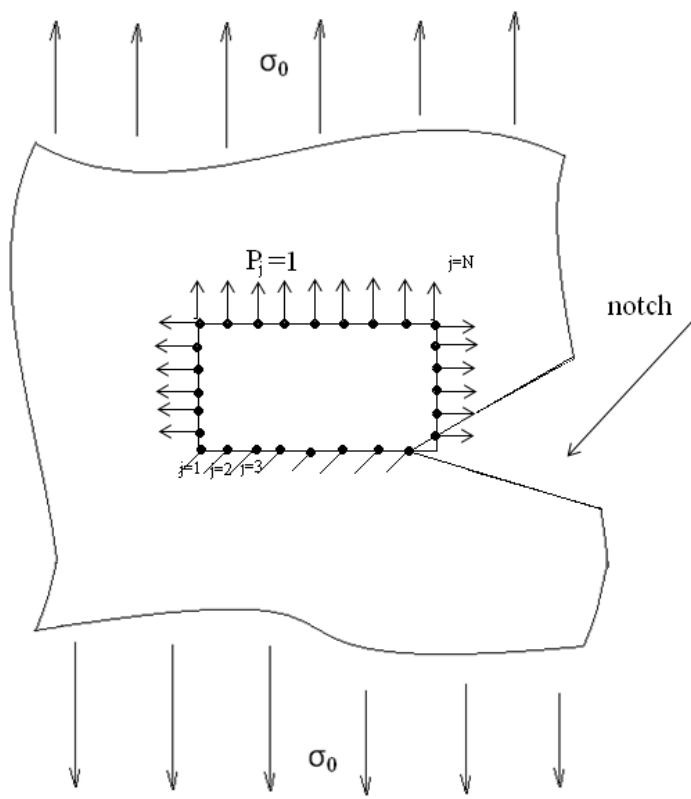

Fig. 4. Scheme for determining the stress components of specimen with a notch.

The figure 4 shows specimen containing a notch. The sample is subjected to a tensile loading. A side of the region is divided points which are selected for the application of external load. The external unit loads along the boundary are applied so that they vary linearly from zero to unity value between two neighboring points. This way of distribution of loads is commonly used in the boundary element method (FEM), i.e. the unit load in this case is defined so that the load is continuously distributed between 3 neighboring discretized points and the magnitude of force at the midpoint is unit and the magnitude between the midpoint and the two neighboring points at both sides decreases linearly from unit to zero. The stresses in side were calculated using Finite Elements Method. Instead of measuring the stress invariant $\mathrm{J}$ using the thermoelastic stress analysis, we obtain the sum principal stress at points inside.

Figure 5 shows the calculated stress components for a speciment with a notch angle of 30 degrees.
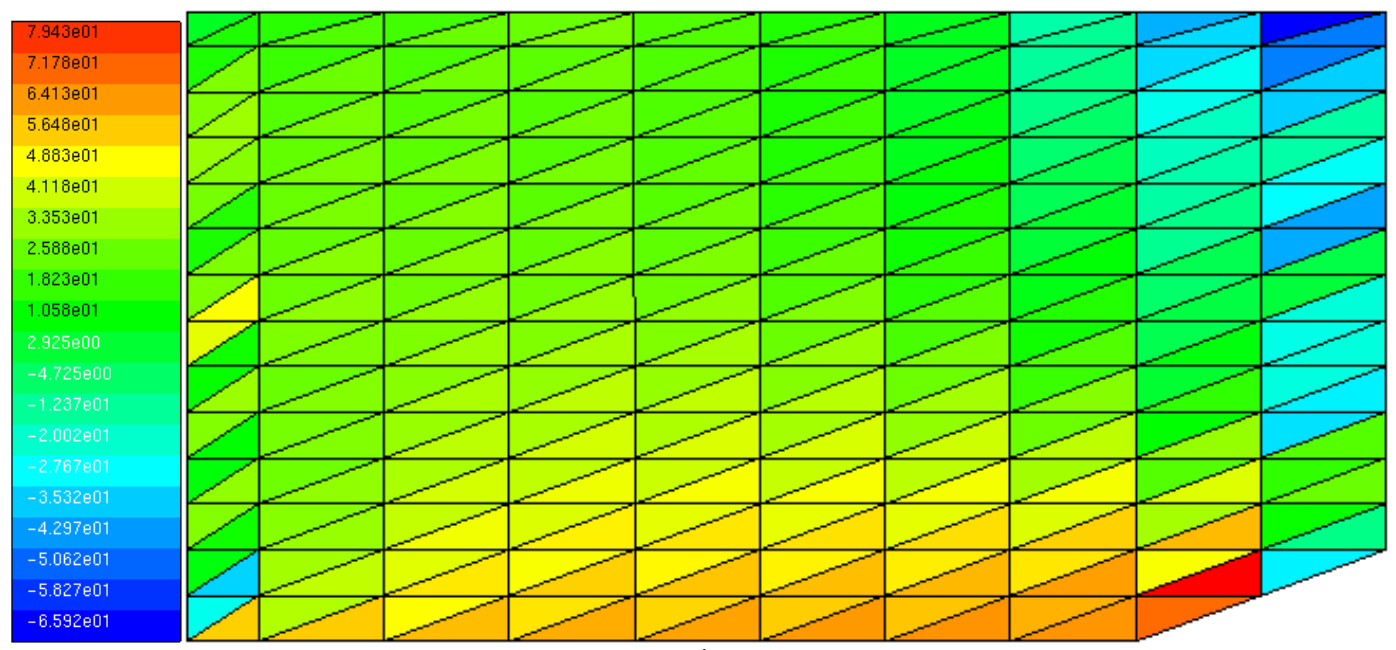

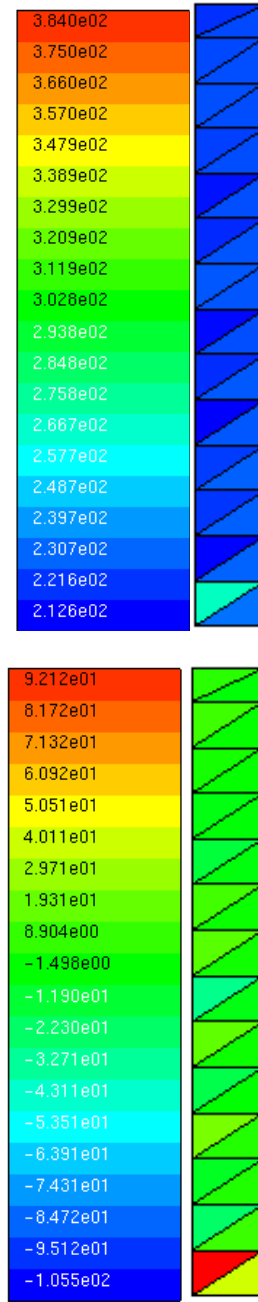

b)

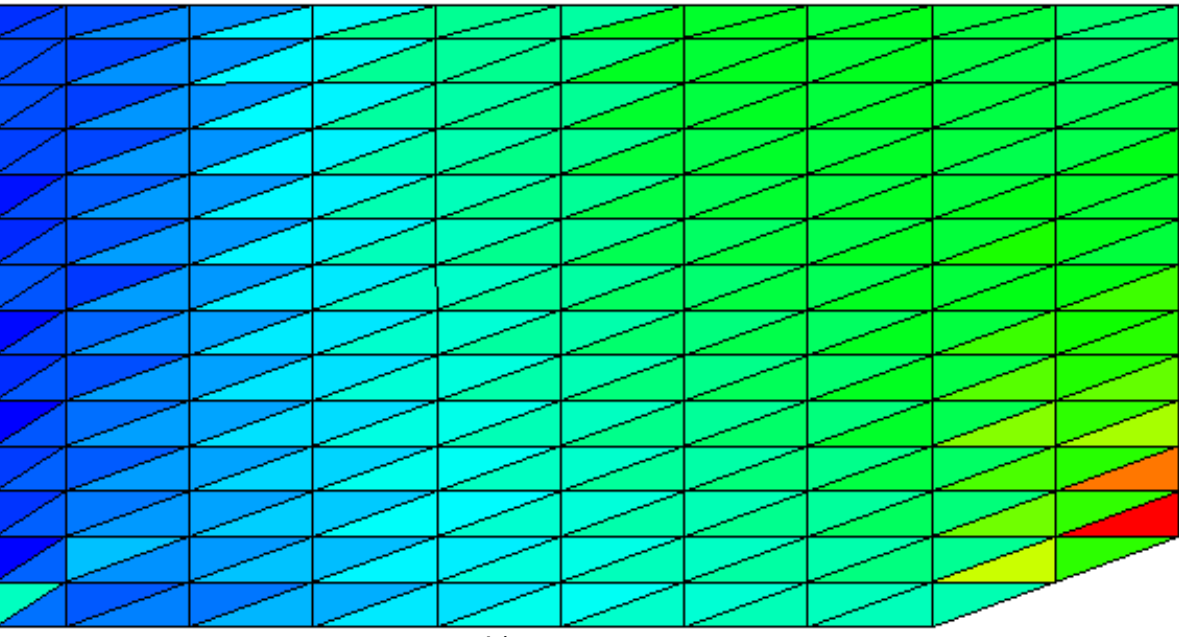

Fig. 5. Stress components of specimen with a notch a) $\sigma_{x x}$, b) $\left.\sigma_{y y}, c\right) \sigma_{x y}$.

Thus, for estimation of stress components at the stress concentrator we need only the information of the first stress invariant on surface and the geometry of the structure.

\section{Conclusion}

It is impossible in principle to determine all stress components by thermoelastic analysis because only the stress invariant of the first order is measured by this method, so a theoretical-experimental methodology for determining all the components of stress tensor of the object was proposed. The stress field near concentrators for different geometry was constructed. The all stress components are determined using of thermoelastic stress analysis and numerical stress analysis (Finite Elements Method), basing on the experimental measurements of temperature. Methodology for the resolution of all stress components has passed through the tests for known analytical solutions and demonstrated good results. These results can open the possibilities for to predict the fracture behavior of structures. This results of the present work is practically very important, because we do not need to analyze a whole structure by FEM using a powerful computer and we only need concern ourselves with the local domain where the thermoelastic stress analysis will be made and define the boundary inside which we apply the above method.

\section{Acknowledgement}

The work is partially supported by grants RFBR (№12-01-33072, №14-01-96005)

\section{REFERENCES}

[1] FedorovaA.Yu., Bannikov M.V., Plekhov O.A.," Infrared thermography study of the fatigue crack propagation". Fracture and Structural Integrity, vol. 21, pp. 46-53, 2012

[2] O. Plekhov and O.Naimark "Theoretical and experimental study of energy storage process in metals under 
http://dx.doi.org/10.21611/qirt.2014.176

plastic deformation", 11th International Conference on Quantitative InfraRed Thermography, paper QIRT2012-191, Naples-Italy, 2012.

[3] Y. Murakami and Yoshimura. "Determination of all stress components from measurements of the stress invariant by the thermoelastic stress method". International Journal of Solids and Structures, Vol. 34 (35-36), pp. 4449-4461, 1997. 